\title{
WILEY-VCH
}

DOI: $10.1002 /$ ((please add manuscript number))

Article type: Full Paper

\section{Excellent nanofiber adhesion for hybrid polymer materials with high toughness based on matrix interdiffusion during chemical conversion}

\author{
Lode Daelemans, Wim Van Paepegem, Dagmar R. D'hooge*, and Karen De Clerck* \\ Department of Materials, Textiles and Chemical Engineering (MaTCh), Ghent University \\ Technologiepark 907, 9052 Zwijnaarde, Belgium \\ E-mail: Karen.DeClerck@UGent.be \\ E-mail: Dagmar.Dhooge@UGent.be
}

Keywords: curing, nanocomposites, bonding strength, nanomorphology control, (coaxial) electrospinning

One of the challenges for multiphase materials is the improvement of the interconnectivity of their separate phases. A promising route towards excellent adhesion is molecular interdiffusion, in which molecules are transferred to enable physical interaction. In the present work, a novel straightforward and direct method is developed to tune the adhesion between electrospun nanofibers and their matrix, starting from fundamental insights on molecular diffusion and considering in situ chemical formation of one of the polymer phases to effectively regulate interdiffusion. Proof-of-concept is provided for the adhesion of a thermoplastic phase (poly( $\varepsilon$-caprolactone)) to a thermoset matrix (epoxy) during the curedinduced formation of the latter. For isothermal curing, only an intermediate temperature $\left(50^{\circ} \mathrm{C}\right)$ allows the production of nanofiber hybrid materials with good adhesion between the constituents and preservation of the nanomorphology. Moreover, excellent adhesion properties are obtained in case a two-step curing $\left(25^{\circ} \mathrm{C} / 80^{\circ} \mathrm{C}\right)$ or coaxial electrospinning (polyamide 6/poly(ع-caprolactone)) toward core-shell nanomorphologies is applied. Improvements in toughness of the optimized interdiffused materials with $G$ values over $600 \mathrm{~J} \mathrm{~m}^{-2}$ (up to $65 \%$ improvement) are recorded due to excellent bonding of the thermoplastic nanofibers with the matrix. 


\section{WILEY-VCH}

\section{Introduction}

For many application fields (e.g. photovoltaics, construction sector, and medicine) multiphase materials are required to allow for a wide portfolio of properties in a single product. A challenge remains the control over the interconnectivity of the separate phases. ${ }^{[1,2]}$ In many studies, interdiffusion has been put forward as an important physical phenomenon influencing the phase interaction. ${ }^{[3-9]}$ For polymeric materials interdiffusion is commonly targeted after polymer synthesis. For example, for solar cells based on P3HT/PCBM bulk heterojunction, it has been highlighted that under annealing conditions PCBM diffuses into the amorphous regions of $\mathrm{P} 3 \mathrm{HT}$, complicating the complete mapping of the morphology and interfacial composition. ${ }^{[4]}$

One can however expect that a stronger interdiffusion and therefore a better regulation of material properties can be obtained in case one of the polymer phases still needs to be formed by chemical reaction. Indeed, from the polymer synthesis field it is known that higher diffusivities are obtained in low viscosity, monomer-rich, environments and the movement from one reactive phase to the other is facilitated at low monomer conversions. For example, at elevated temperature the diffusion of oligomeric radicals from the monomer-rich to the polymer-rich phase in poly(vinyl chloride) synthesis allows to enhance the mechanical properties. ${ }^{[5,6]}$

The enhancement of mechanical properties can also be realized by dispersing reinforcing fillers in a polymer matrix, provided that an excellent adhesion is established between both constituents of the composite. The nano-engineering of polymer composites to improve their structural performance (e.g. toughness) remains an important research task. ${ }^{[10-13]}$ Many types of nanoscale reinforcing fillers exist, with electrospun nanofibers being very promising due to their feasible scale-up, ease of handling, and fiber morphology. ${ }^{[14]}$ These advantages have 


\section{WILEY-VCH}

resulted in significant interest into electrospun veils for nano-engineered polymer composite materials. ${ }^{[15-19]}$ One of the main topics is to incorporate electrospun nanofibrous veils within traditional laminated glass fiber or carbon fiber composites to obtain hybrid composites with both nano- and microscale fibers. ${ }^{[20-23]}$ Incorporating electrospun nanofibers within the damage prone interlayers results in a nano-engineered hybrid laminate with substantial improved fracture toughness. ${ }^{[12]}$ Crucial is again an adequate adhesion with the matrix material to obtain an effective load transfer to the nanofibers. Although the importance of good adhesion for properties such as damage resistance or mechanical performance has been postulated, ${ }^{[12,18,24,25]}$ limited attention has been paid to the determination of adhesion properties between electrospun nanofibers and the matrix material. No direct test methods exist, also inhibiting progress in the field.

In the present work, a novel method - fully exploiting the potential of interdiffusion - is developed to tune the adhesion between electrospun nanofibers and their matrix, starting from fundamental theoretical insights on molecular diffusion and considering in situ formation of one of the polymer phases. To highlight its versatility the method is applied for a thermoplastic material (nanofibers) in combination with a thermoset (matrix). For the former poly( $\varepsilon$-caprolactone) (PCL) is selected and for the latter an epoxy, as their conventional blends have already been well studied. ${ }^{[26-30]}$ The method is based on the intermolecular mixing of PCL and epoxy molecules during curing of the latter. Advantageously, it requires no special processing steps compared to other adhesion improving methods, such as plasmatreatment, ${ }^{[31]}$ and (chemical) surface modification, ${ }^{[32]}$ and is therefore a direct appealing method. The insights allow to develop well-defined nano-engineered hybrid materials, with a variation in the nanofiber PCL/epoxy interfacial strength allowing to control crucial properties such as the toughness. 


\section{WILEY-VCH}
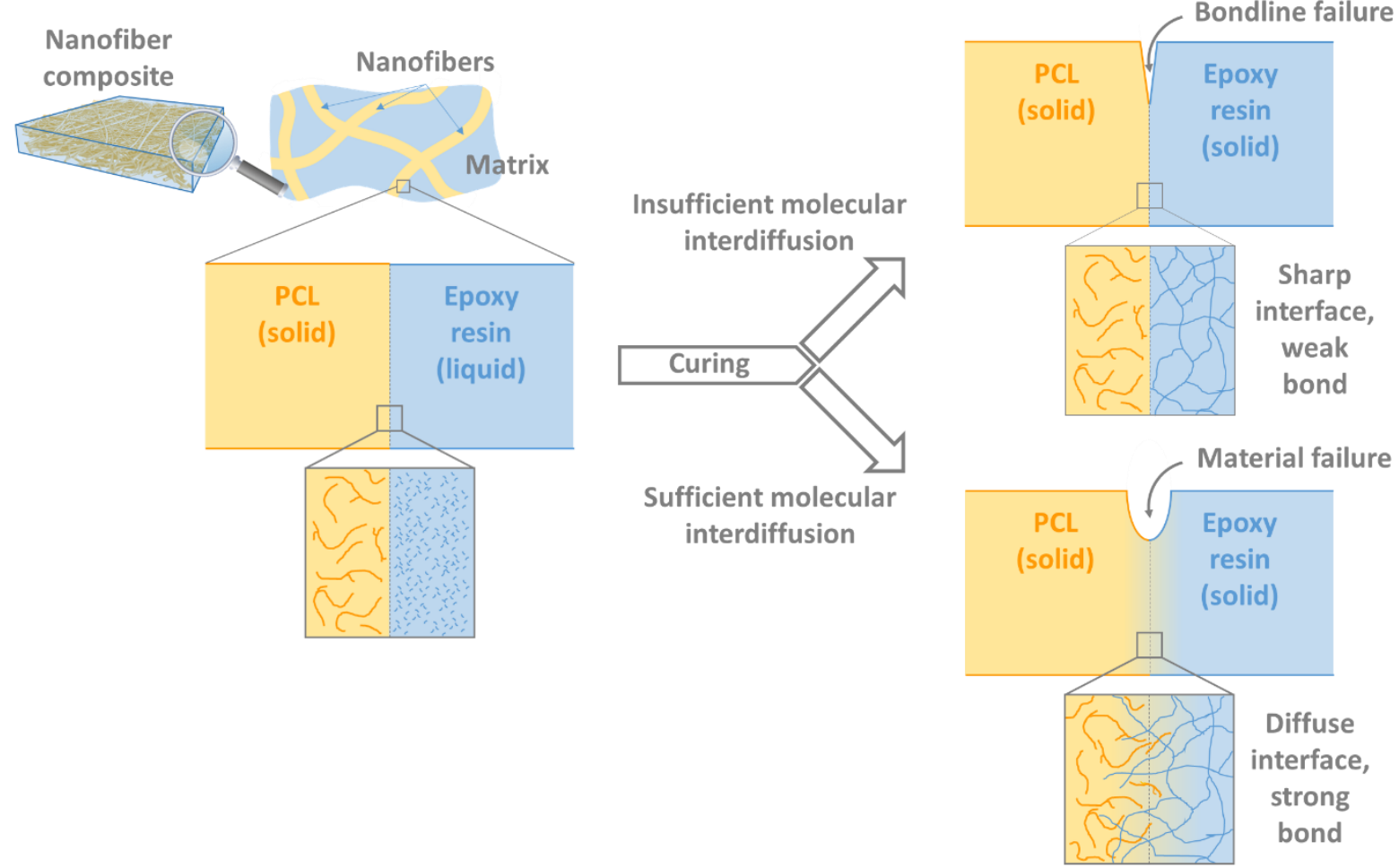

Figure 1: Principle of interdiffusion with chemical reaction (here curing of epoxy resin) to allow for excellent adhesion between both polymer phases (here PCL and epoxy) at the end of the reaction. Sufficient molecular interdiffusion is crucial to ensure the desired adhesion (top vs. bottom; right). A too strong interdiffusion can however destroy the desired nanomorphology.

\section{Principle of method: exploitation of interdiffusion with chemical reaction}

Interdiffusion during curing, as put forward in the present work, aims at the physical bonding between polymer phases (here PCL and epoxy), during the formation, hence, chemical conversion of one of them (here curing of the epoxy resin). It relies on the diffusion of molecules as present or formed at lower curing times across the interface, as illustrated in

Figure 1 zooming in at one of the many interfaces in a nano-engineered composite. It somewhat resembles the technique of solvent bonding, although no dedicated solvents are used and the solvent is transformed by chemical reaction into a thermosetting polymer phase. It should be stressed that PCL is an ideal reference thermoplastic material as it dissolves readily in many epoxy types, ${ }^{[29,33]}$ and can therefore be employed to obtain a strong interfacial bond between the epoxy resin and PCL polymer through a diffuse interface. 


\section{WILEY-VCH}

A crucial research question that arises is to which extent the molecular diffusion can be regulated to ensure sufficient adhesive strength at sufficiently large reaction time (bottom of Figure 1; right) as opposed to the case of weak bonding with no or limited interdiffusion (top of Figure 1; right). The formation of a strong bond between two phases depends on the size of the interdiffusion layer and the concentration gradients in this layer, with a too strong diffusion likely leading to a disruption of the structured nanomorphology. Assuming that PCL is sufficiently mobile to diffuse toward the epoxy resin phase at the weight percentages encountered in nanofiber interleaved laminates $\left(0.25-1 \mathrm{~m} \%^{[34]}\right)$, the size of the layer will be governed by the PCL dissolution rate, which is related to its molar flux.

The measurement of the layer size or flux is extremely tedious if not impossible and, hence, support from theory is recommended. Though certain models exist to predict the dissolution rate of semi-crystalline polymer fibers, ${ }^{[35]}$ they are very complex and dependent on many parameters that are difficult to determine experimentally. Moreover, in the present work, the epoxy resin increases in viscosity over time due to chemical reaction, forms a network and eventually cures into a solid material so that interdiffusion can only take place at the lower epoxy resin conversions at which the molecular structure has not been fixated yet. The change in aggregation state due to increased epoxy resin conversion lowers the solubility of the PCL molecules drastically, affecting the overall dissolution rate, and can even result in phase separation. ${ }^{[36,37]}$

Hence, in the present work, a novel analytical model is constructed for which the stepwise derivation is included and discussed in detail in Section S1 and Section S2 of the Supporting Information. This time dependent model reflects the diffusion kinetics through a fundamental two-film layer approach (Figure 2a) as long as no strong network formation, which occurs at the higher times, has taken place. The molecular diffusion of a species type (e.g. PCL macrospecies) from one phase to the other is described as a sum of two resistances (one for 


\section{WILEY-VCH}

each phase, corresponding to two film layers), assuming equilibrium at the phase interface.

Importantly, the analytical model corrects the molecular diffusivities for chain length

dependencies and time dependent compositional changes, hence, fully accounts for reaction in one of the phases.

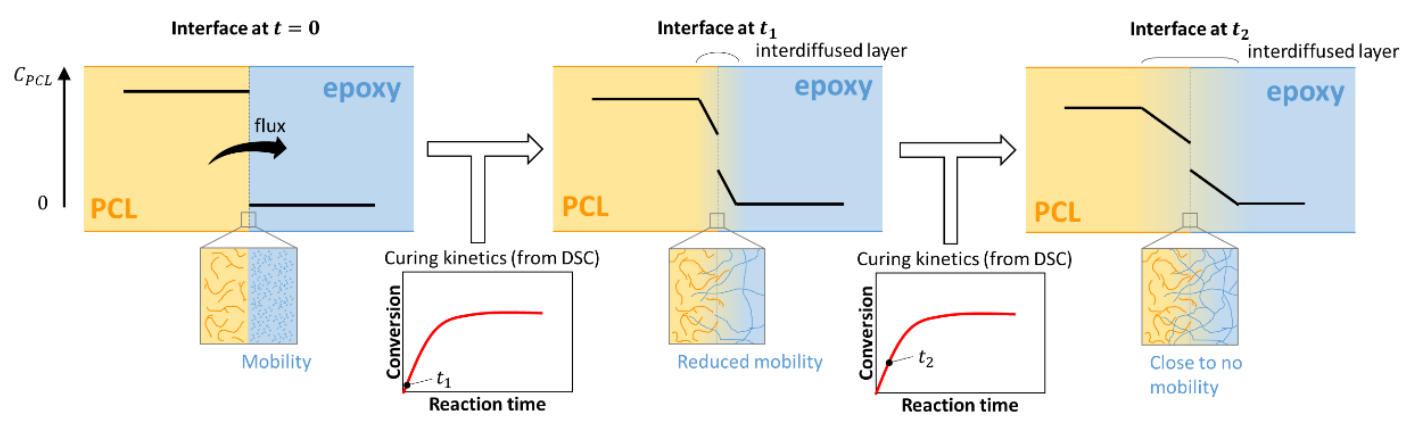

(a)

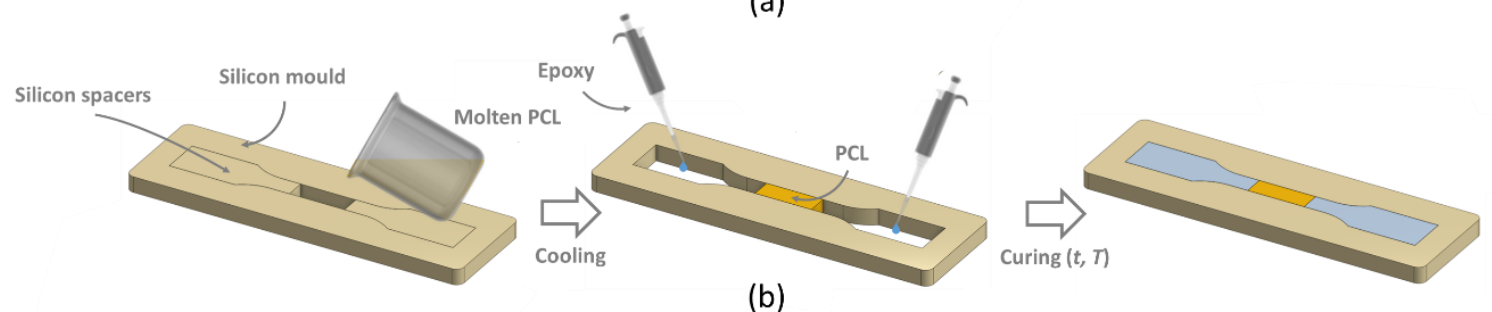

(b)

Figure 2: (a) Two-film analytical model for the translation of the interdiffusion concept with reaction. This model allows to calculate at times before strong network formation (fixation) the molar flux from one phase to the other while accounting for chain length dependencies and time dependent compositional changes due to the chemical curing of the resin. The latter is done by feeding time dependent measured DSC data covering the mass fraction change due to resin conversion (red curves) to the analytical model (full details in Section S1 and S2 of the Supporting Information); (b) PCL/epoxy reference system for proof-of-concept of the developed method; this system is selected to obtain well-defined clear interfaces and a direct link with the developed diffusion model.

The main equation of the analytical model is provided below and allows to calculate at a given time $t$ the molar flux of PCL $\left(J_{t}\right)^{:[5,38,39]}$

$$
J_{t}=\frac{\left(C_{1, t}-\Gamma C_{2, t}\right)}{\left(\frac{1}{k_{1}}+\frac{\Gamma}{k_{2}}\right)}
$$

In Equation (1), $C_{i, t}$ is the "bulk" concentration in phase $i$ at $t, \Gamma$ the PCL partitioning coefficient defined as the ratio of the equilibrium concentration of phase 1 (PCL) and the 


\section{WILEY-VCH}

equilibrium concentration of phase 2 (epoxy), and $k_{i}$ the mass transfer coefficient for phase $i$.

The latter is at any time proportional to the diffusion coefficient $\left(D_{i}\right)$. As explained in Section $\mathrm{S} 1$ of the Supporting Information, $D_{i}$ is calculated with the so-called free volume theory as commonly applied to describe diffusional limitations in polymerizations with strongly increasing viscosities. ${ }^{[37,40,41]}$ In this theory, $D_{i}$ is explicitly a function of the temperature and the mass fractions in phase $i$ so that the change in composition in the resin phase $(i=2)$, leading to lower mobility can be accounted for. This is done by feeding time dependent differential scanning calorimetry (DSC) curing data on the progress of the resin conversion under isothermal conditions to the diffusion coefficients in the analytical model (e.g. Figure 2(a) at $t_{1}$ and $t_{2}$ ). Hence, model validation is performed for the actual resin system based on measured compositional data. For other parameters, typical values for literature are selected or universal scaling laws are considered. It should be stressed that this diffusion model only aims at the correct reflection of qualitative trends and further tuning of its model parameters is still possible in a later stage but beyond the scope of the present work. As such the formulated insights are general and for related materials it can be stated that similar diffusion profiles as the ones optimized in the present work need to be mimicked.

\section{Results and Discussion}

\subsection{Proof-of-concept and fundamental interpretation of method}

Double butt-jointed tensile specimens are manufactured to study the concept of interdiffusion at PCL/epoxy interfaces, as obtained at different curing temperatures. These specimens consist of a PCL beam bonded at both sides with epoxy (Figure 2b) and are therefore characterized at each side by a very clear interface. This explains why this experimental configuration has been considered for the proof-of-concept as it allows to study the intrinsic relevance of interdiffusion. As highlighted in the experimental section, the PCL beam is first made and then curing of the epoxy resin is performed. If a specimen breaks at the bond line 


\section{WILEY-VCH}

due to adhesive failure, the maximum stress is a measure for the interfacial strength. If the specimen fails by bulk failure however, hence, cohesive failure occurs, the interfacial strength is sufficient and the bond is no longer the weakest point in the specimen. As the tensile strength of bulk PCL $(14.0 \pm 1.5 \mathrm{MPa})$ is much lower than that of epoxy $\left(65 \mathrm{MPa}^{[42]}\right)$, bulk failure is established in the PCL phase.

A negligible strength is obtained in case the epoxy is cured before it is brought into contact with PCL, highlighting the necessity of interdiffusion. For cure temperatures between $25^{\circ} \mathrm{C}$ and $35^{\circ} \mathrm{C}$, adhesive failure takes place due to limited interfacial strength between PCL and epoxy by limited interdiffusion (Figure 3a). Nevertheless, the interfacial strength increases from 2.6 $\pm 0.9 \mathrm{MPa}$ at a cure temperature of $25^{\circ} \mathrm{C}$ to $5.0 \pm 1.5 \mathrm{MPa}$ at a cure temperature of $35^{\circ} \mathrm{C}$. This twofold increase can be explained by the improved dissolution rate of PCL at higher temperatures, as supported by the analytical simulation results in Figure 3b-c. These results indicate higher fluxes and thus faster increases of the PCL concentration in the resin phase at higher temperatures. Hence, the longer diffusion times at lower curing temperatures (slower resin kinetics) are not beneficial as the diffusivities are too low at those temperatures. At cure temperatures equal to or above $40^{\circ} \mathrm{C}$, the interfacial strength in Figure 3a becomes higher than the bulk PCL yield strength and cohesive failure therefore takes place. From these temperatures onwards, the cumulative molecular diffusion between both phases is sufficient, allowing a sufficiently high PCL concentration (Figure 3c), resulting in the formation of strong bonds by the interdiffusion effect. Thermal analysis of the semi-crystalline PCL with DSC showed that at $40^{\circ} \mathrm{C}$ the onset of the melting endotherm is reached, increasing the mobility of the PCL crystallite polymer chains which positively influences the dissolution rate.

In Figure 3d, SEM images of the fracture surfaces of the butt-jointed tensile specimens for different cure temperatures confirm the existence of the interdiffused interfaces at higher 


\section{WILEY-VCH}

temperatures. Specimens with a low interfacial strength (2 $\mathrm{MPa})$ show relatively smooth

surfaces without clear signs of good adhesion between both phases. For specimens with a

higher interfacial strength (6 MPa), fused spots are visible which show some plastic

deformation. At these spots, more PCL dissolution took place, resulting in a more diffuse

boundary. At curing temperatures of $40^{\circ} \mathrm{C}$ and above, bulk material failure occurred and the

fracture surface shows a high degree of plasticity typical for PCL bulk failure.

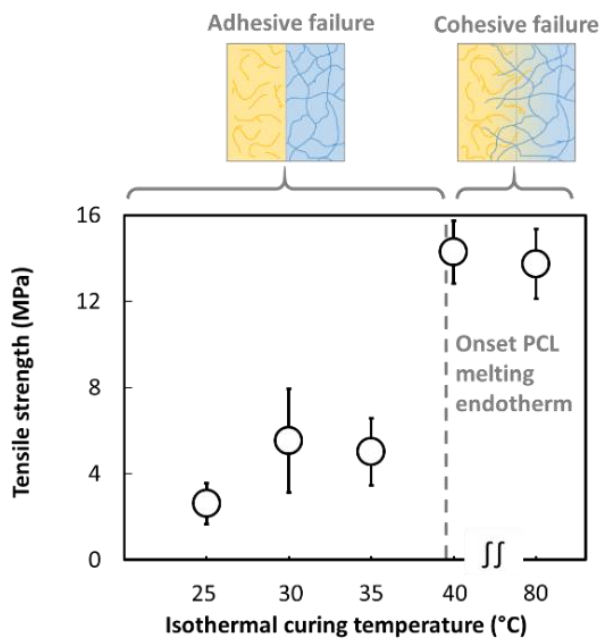

(a)

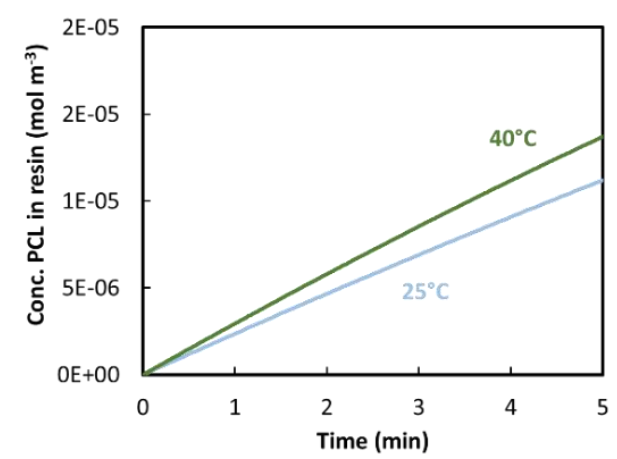

(c)

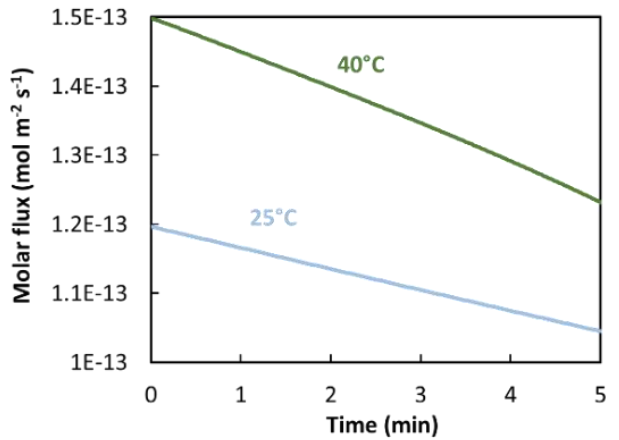

(b)

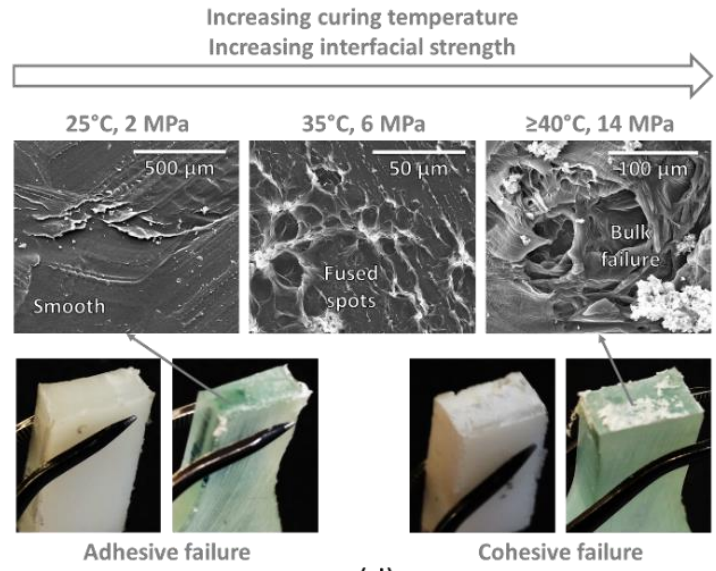

(d)

Figure 3: (a) Tensile strengths for proof-of-concept with butt-jointed tensile specimens enabling focus on clear interfaces (Figure 2). Curing temperatures between $25^{\circ} \mathrm{C}$ and $8^{\circ} \mathrm{C}$ are considered leading to a change from adhesive to cohesive failure; (b) Predictions of the molar flux and (c) increase in PCL concentration in the resin phase for a "low" $\left(25^{\circ} \mathrm{C}\right)$ and a "high" $\left(40^{\circ} \mathrm{C}\right)$ curing temperature (cf. Equation (1) and details in the Supporting Information) at the lower times (before fixation) to theoretically support the findings; (d) Change in fracture surface morphology from adhesive to cohesive failure at higher curing temperatures $\left(\geq 40^{\circ} \mathrm{C}\right)$; all data under isothermal 


\section{WILEY-VCH}

conditions; simulations lines account for the composition change due to reactions (DSC data in Figure S2 of the Supporting Information).

\subsection{Application of method for nanofiber hybrid composite materials under isothermal conditions}

The principle of the interdiffusion due to high temperature curing is exploited to produce high toughness nano-engineered composite laminates with different degrees of nanofiber/matrix bond strength by interleaving electrospun PCL nanofibrous veils in between reinforcing glass fiber plies, i.e. creating similar interfaces as in the proof-of-concept system albeit at a smaller scale with possible associated slight differences in the diffusion process. The stacking of dry glass fiber plies and nanofibrous veils is infused with unreacted epoxy resin and isothermally cured. Unmodified reference composite laminates are produced for comparison. Under opening mode (so-called Mode I) of specially designed delamination specimens, the nanofibers are subjected to peeling forces which can result in debonding of the nanofibers if the interfacial strength is weak (Figure 4a, right). ${ }^{[22]}$ The nanofibers are then not stretched and the (Mode I interlaminar fracture) toughness $G$, which is a good measure for the interfacial strength between the PCL nanofibers and the epoxy matrix, will hardly be improved. ${ }^{[12]}$ Three isothermal cure temperatures are selected based on the proof-of-concept section, i.e. $30^{\circ} \mathrm{C}, 40^{\circ} \mathrm{C}$ and $50^{\circ} \mathrm{C}$. Even higher isothermal curing temperatures $\left(60^{\circ} \mathrm{C}\right.$ and $80^{\circ} \mathrm{C}$ ) result in a very strong interdiffusion of the nanofibers but an unwanted loss of the nanomorphology. Note that curing is performed until the reaction stops, and the time-scale for this reaction decreases with increasing temperature (input from DSC measurements).

The $G$ value of the unmodified reference (virgin) and PCL nanofiber interleaved composites are shown in Figure 4a. For the virgin specimens, the cure cycle has no impact and $G$ is therefore given by a representative value equal to $409 \pm 35 \mathrm{~J} \mathrm{~m}^{-2}$. For the nanofiber interleaved specimens, the observation from Figure 3a can be identified with an increase in 


\section{WILEY-VCH}

curing temperature resulting in a higher interfacial strength and therefore a higher $G$ due to better load transfer. For nanofiber interleaved specimens cured at $30^{\circ} \mathrm{C}$ and $40^{\circ} \mathrm{C}$, there is no or only a small increase in $G$ compared to the virgin material $\left(486 \pm 55 \mathrm{~J} \mathrm{~m}^{-2}\right.$ and $404 \pm 55 \mathrm{~J} \mathrm{~m}^{-2}$ ), again demonstrating that a sufficiently high temperature is needed to ensure sufficient molecular diffusion. The slightly higher increase in $G$ for specimens cured at $30^{\circ} \mathrm{C}$ compared to $40^{\circ} \mathrm{C}$ can be understood based on the analytical modeling insights. This is likely due to an increased reaction time for the epoxy, allowing diffusion to take place over a larger time frame before network fixation takes place. However, more important, for specimens cured at $50^{\circ} \mathrm{C}$, a relatively large improvement of $44 \%$ in $G$ is obtained $\left(587 \pm 98 \mathrm{~J} \mathrm{~m}^{-2}\right)$ with a maximal measured value of $720 \mathrm{~J} \mathrm{~m}^{-2}$. Note that for other polymers also an optimal temperature is to be expected, which can be identified with the diffusion model by mimicking the molar flux evolution as obtained in the present work.

Analysis of the fracture surfaces by SEM (Figure 4b) confirms the development of a strong interfacial interaction between the nanofibers and the matrix at curing temperatures of $50^{\circ} \mathrm{C}$. For too low cure temperatures of $30^{\circ} \mathrm{C}$ and $40^{\circ} \mathrm{C}$ (low improvement in $G$ ), the SEM images reveal that the nanofibers are prone to debonding from the epoxy matrix. Clearly, outlined nanofibers as well as imprints left by peeled nanofibers are visible on the fracture surface. For specimens cured at $50^{\circ} \mathrm{C}$ (high improvement in $G$ ), SEM analysis demonstrates that the nanofibrous morphology is still present (though less clear than for specimens cured at lower temperatures) and that there are clear signs of a better interfacial strength. The SEM insert shows crazing at the nanofiber/matrix interface due to a strong interfacial bond.

For the nanofiber engineered composite, the onset of sufficient interfacial strength shifts to higher temperatures compared to the proof-of-concept system (at least $10^{\circ} \mathrm{C}$; proof-of-concept system (Figure $\mathbf{2 b - 3}$ ) lower temperature of $40^{\circ} \mathrm{C}$ ). This is likely due to a difference in dissolution and melting kinetics of nanofibrous PCL compared to macroscopic bulk PCL 


\section{WILEY-VCH}

(non-equilibrium vs. equilibrium polymer chain conformation) and restrictions due to the infusion method. Yet there is a maximum temperature that can be exploited $\left(<60^{\circ} \mathrm{C}\right)$, before the interdiffusion mechanism leads to complete dissolution. As opposed to the proof-ofconcept case, where the PCL phase is present in bulk, a nanofiber sized PCL phase is rapidly depleted and completely dissolved, complicating the design of the optimal operating window and justifying further process design in the following section.
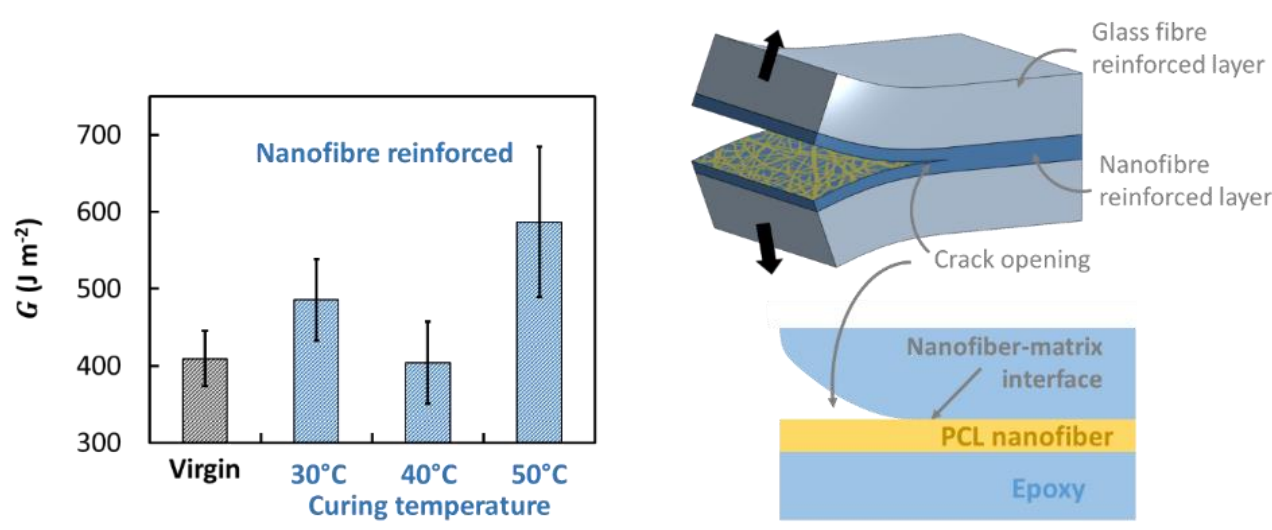

(a)
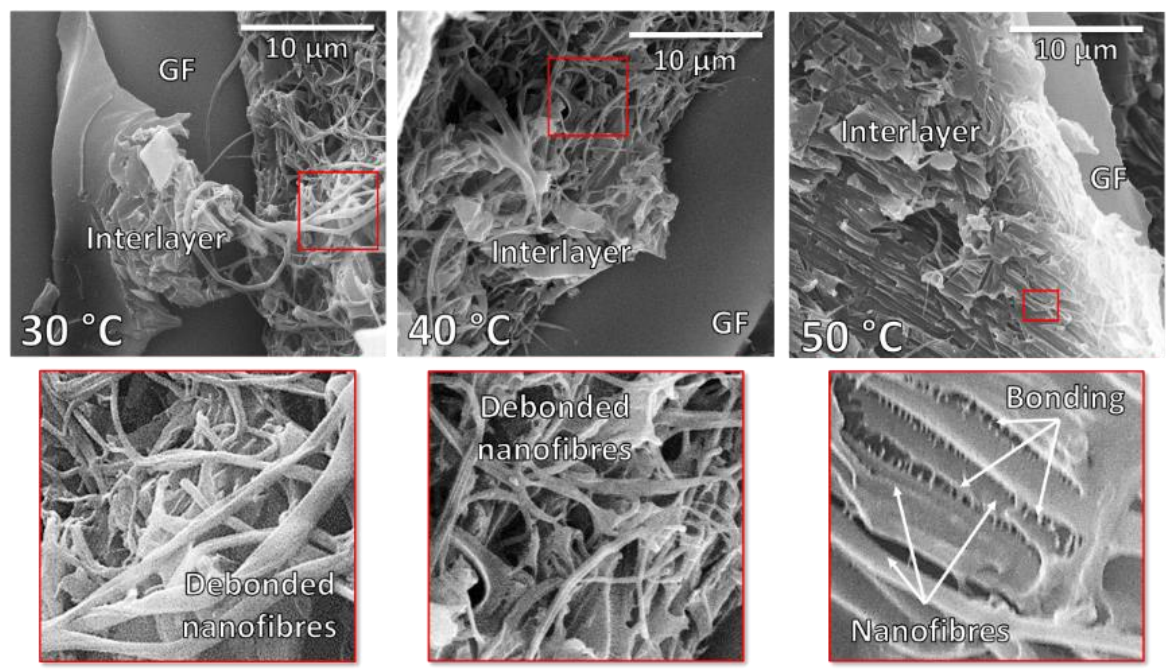

(b)

Figure 4. (a) Effect of curing temperature on the toughness $G$ (left), a measure for the interfacial strength of the PCL nanofibers and the epoxy (right); (b) SEM images of fracture surfaces at the 3 curing temperatures in (a); only for a curing temperature of $50^{\circ} \mathrm{C} \mathrm{a}$ substantial increase in adhesive strength is combined with a preservation of the nanomorphology. Hence, a maximal curing temperature $\left(50^{\circ} \mathrm{C}\right)$ exists under isothermal 


\section{WILEY-VCH}

conditions, justifying further optimization as covered in Figure 5 (step-wise curing) and Figure 6 (coaxial electrospinning).

\subsection{Broadening the application potential with a two-step curing program and coaxial electrospinning}

The preservation of the structured nanomorphology is crucial for toughness improvements as well as for many other applications where adhesion is at stake. The interdiffusion mechanism should therefore be limited to a very small zone near the interface of both materials. Indeed, while the adhesion can be drastically improved by interdiffusion, too much of it leads to a loss of the nanostructured morphology due to complete dissolution. A viable option to broaden this application potential is to work towards "core-shell" structured nanomorphologies, in which the shell, i.e. the outer layer in direct contact with the matrix, provides adhesion by interdiffusion, while the core provides the nanomorphology.

A first optimization of the interdiffusion concept in view of high-performance core-shell structured nanofiber hybrid materials is the consideration of a stepwise temperature curing program, with a first step below the PCL melting temperature $\left(T_{m, P C L}\right)$ and a second step above the latter temperature, schematically reflected in Figure 5a. It is important that the time and temperature of the first curing step is chosen such that the epoxy is still converted sufficiently fast in a pre-network structure to maintain the nanofiber morphology as a sort of self-formed mold (core formation), while still "open" enough to allow for sufficient mixing between PCL and epoxy molecules at elevated temperature (shell formation). The added value is that the epoxy resin can be fully cured during the second step at higher temperature. This increases the glass transition temperature and is needed for better mechanical properties. The toughness achieved using two different two-step curing programs is compared to the isothermal data in Figure 5b (green vs blue bars): (i) isothermal cure at $40^{\circ} \mathrm{C}$ for 50 hours, followed by post-cure at $80^{\circ} \mathrm{C}$ for 15 hours; and (ii) partial cure at room temperature for 24 hours, followed by post-cure at $80^{\circ} \mathrm{C}$ for 15 hours. The main difference between both 


\section{WILEY-VCH}

programs is the conversion of the epoxy reached after the first curing step (same conversion is reached after the second curing step). DSC measurements show that isothermal curing at $40^{\circ} \mathrm{C}$ yields a $T_{g}$ around $60^{\circ} \mathrm{C}$ (indicative of a high conversion), while the partial cure at room temperature only yields a $T_{g}$ of around $22^{\circ} \mathrm{C}$ (indicative of a low conversion). A too high conversion in step one may lead to insufficient diffusion of the PCL chains into the epoxy network during the second, high temperature, curing step and thus limited interdiffusion. Indeed, for cure cycle (i), $G$ is only slightly improved $\left(466 \pm 60 \mathrm{~J} \mathrm{~m}^{-2}\right)$. In contrast, the limited conversion during the first step of cure cycle (ii) allows for the formation of a sufficient diffuse boundary between PCL and epoxy during the second curing step, improving $G$ substantially with a value well-above $600 \mathrm{~J} \mathrm{~m}^{-2}\left(645 \pm 27 \mathrm{~J} \mathrm{~m}^{-2}\right)$ compared to the virgin material and above the best value for isothermal curing. This is confirmed by SEM analysis, which shows nanofibers that adhere well to the epoxy (Figure 5c).

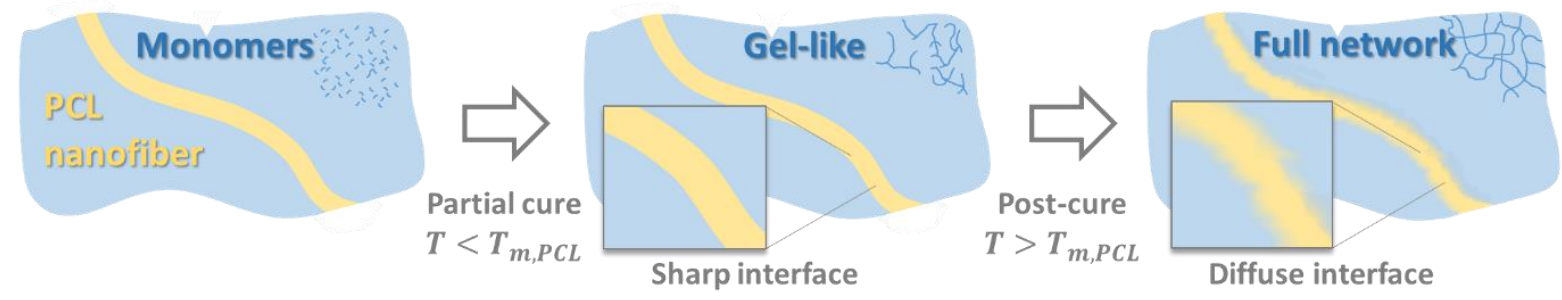

(a)

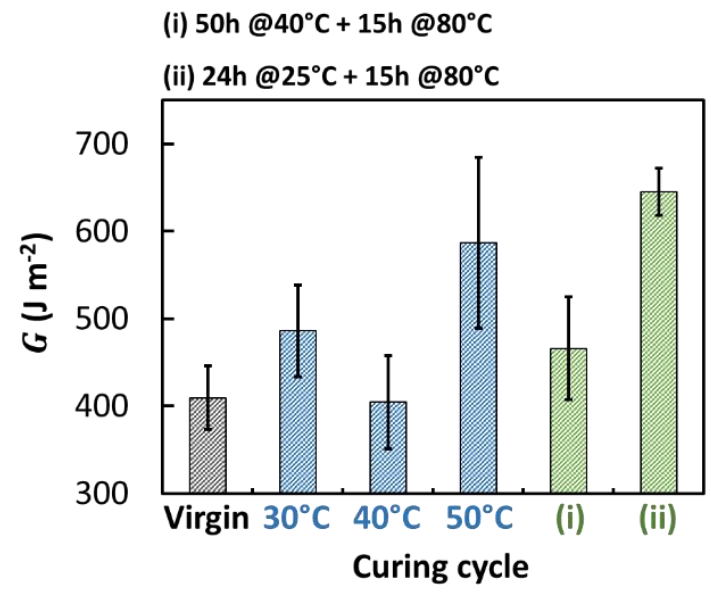

(b)
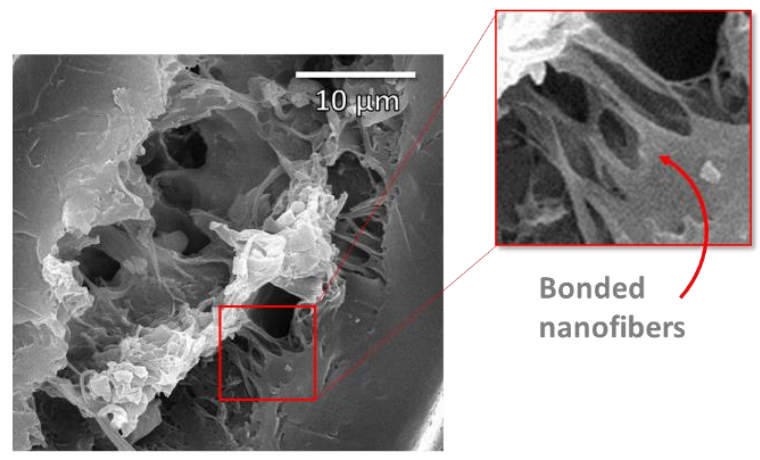

Figure 5: (a) Schematic representation of the two-step curing method, aiming at "coreshell" kind of morphology to increase the potential of the method as explored under 


\section{WILEY-VCH}

isothermal conditions (Figure 4). In the first step at low temperature a sufficiently strong network formation is obtained for the epoxy to avoid complete dissolution later on. In the second step, interdiffusion takes place at elevated temperature to ensure the increase in adhesion strength; (b) Comparison of data on toughness for this two-step method with data under isothermal conditions; only cycle (ii) is useful as it combines a low conversion for the first step with a high temperature for the second step; (c) SEM image of the fracture surface for a specimen cured according to cure cycle (ii) showing excellent adhesion with the matrix.

A second optimization strategy to obtain good bonding and maintain the nanofiber morphology is the use of electrospun core-shell bimaterial nanofibers, as attainable with coaxial electrospinning. Apart from the requirement of a coaxial needle, this technique resembles regular electrospinning and is therefore also capable of producing nanofibrous veils for nano-engineered composites. By selecting a polymer that is (almost) not affected by the interdiffusion mechanism (core) and a polymer capable of interdiffusing with the epoxy resin (shell), good adhesion without any loss of the nanofibrous morphology can be obtained, as illustrated schematically in Figure 6a. The core and shell of the nanofibers can consist of different polymers, or even the same polymer type but with different average molar masses so that different dissolution rates are obtained. Moreover, some interdiffusion, and thus a proper adhesion, between the core and the shell can be anticipated as both solutions are typically spun from the same solvent and come into contact in the solution phase in the coaxial needle. 


\section{WILEY-VCH}
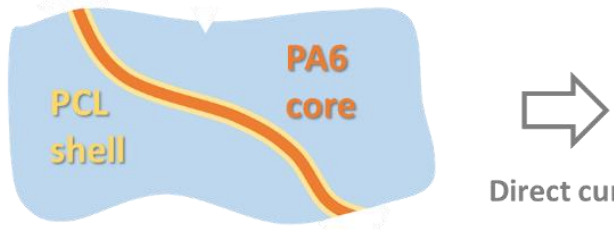

Direct cure

(a)

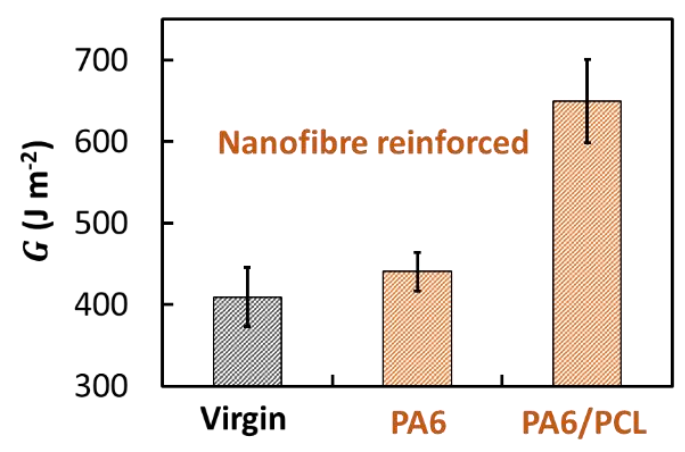

(b)
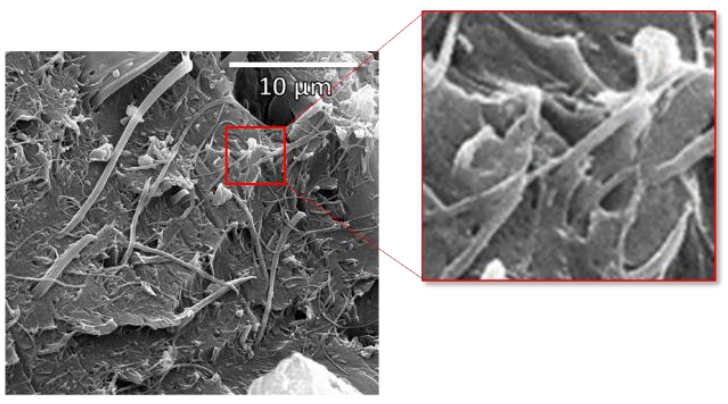

(c)

Figure 6: (a) Schematic representation of the potential of core-shell nanofibers from coaxial electrospinning with interdiffusion between the shell and the curing epoxy resin; (b) Data on toughness of core-shell nanofiber specimens (PA6/PCL core-shell nanofiber) and comparison with virgin and single component nanofiber specimens; (c) Fracture surface of a core-shell modified specimen shows good nanofibrous morphology due to the PA6 core and good adhesion by interdiffusion of the PCL shell.

In the present work, focus is restricted to the polymer pair polyamide 6 (PA6) and PCL.

Previous research has indicated that PA6 nanofibers maintain their morphology at common curing temperatures $\left(T_{m, P A 6}=220^{\circ} \mathrm{C}\right)$, but result in limited improvements of fracture toughness due to a low adhesion with epoxy. ${ }^{[12,21,43]}$ The coaxial electrospinning technique is used to produce 70/30 m\% PA6/PCL core-shell nanofibers. The specimens were made similar to the single component nanofiber interleaved composites with a single curing step at $80^{\circ} \mathrm{C}$ to obtain a high conversion of the epoxy resin, limit the overall curing time and allow for a large amount of interdiffusion to take place. The fracture toughness of reference laminates and hybrid laminates containing PA6 nanofibers or PA6/PCL core-shell nanofibers are shown in

Figure 6b. Compared to the materials with single component PA6 nanofibers $\left(432 \pm 22 \mathrm{~J} \mathrm{~m}^{-}\right.$

${ }^{2}$ ), the materials with core-shell structured nanofibers result in high toughness improvements 


\section{WILEY-VCH}

$\left(650 \pm 50 \mathrm{~J} \mathrm{~m}^{-2}\right)$, hence, again a value above $600 \mathrm{~J} \mathrm{~m}^{-2}$. This indicates that the bonding is increased due to the PCL shell interdiffusion, while the nanofiber morphology remains due to the PA6 core which is hardly affected by the interdiffusion mechanism. Analysis of the fracture surface with SEM (Figure 6c) indeed shows clearly distinguishable nanofibers which bridge cracks without significant debonding of the nanofibers.

\section{Conclusion}

A straightforward and direct method enabling to control the interfacial bonding between two polymers is proposed based on molecular interdiffusion with one of the polymer phases formed in situ. Proof-of-concept is successfully demonstrated based on tensile specimens composed of thermoplastic PCL in contact with cured epoxy resin at a very clear interface. An increase of the cure temperature causes an enhanced interfacial strength, as a more efficient diffusion can take place over the interface until network fixation is obtained, as supported by theoretical developments focusing at times before fixation takes place and accounting for compositional changes. At temperatures equal to or above the melting onset of PCL the interfacial strength however exceeds the bulk PCL strength and specimens become characterized by bulk PCL failure.

The knowledge obtained on the tensile specimens has been exploited to produce nanofiber interleaved composite laminates with enhanced delamination resistance. The results show that good bonding between the nanofibers and the resin is essential to improve the delamination resistance. In line with the tensile specimens, an increase of the curing temperature enhances the interlaminar fracture toughness. However, for a too high curing temperature, the nanofiber morphology disappears due to complete dissolution of PCL into the epoxy. Hence, the inherent size of nanofibers is a limiting factor, requiring careful design.

To circumvent the previous limitation two optimization strategies have been developed that result in a core-shell structured nanomorphology. The first strategy relates to the use of a two- 


\section{WILEY-VCH}

step curing program with a first lower temperature cure to enable the formation of a pre-network structure that ensures the nanofiber morphology, and a second higher temperature curing step to promote interdiffusion toward enhanced delamination resistance. The second strategy relates to interdiffusion with bimaterial core-shell nanofibers as achievable with coaxial electrospinning in which the outer PCL layer allows for interdiffusion while maintaining good interaction with the PA6 core. With both strategies the high toughness is reflected by a $G$ value above $600 \mathrm{~J} \mathrm{~m}^{-2}$. 


\section{WILEY-VCH}

\section{Experimental Section}

Double butt-jointed tension test for proof-of-concept. The double butt-jointed tensile specimens were produced as illustrated in Figure 2 and consisted of a short PCL beam bonded at both sides with epoxy. The narrow section of the dog bone had a length and width of $50 \mathrm{x}$ $10 \mathrm{~mm}^{2}$ respectively. PCL (Sigma-Aldrich, $M_{n} 80000 \mathrm{~g} \mathrm{~mol}^{-1}$ ) is allowed to melt at $90^{\circ} \mathrm{C}$ and casted as a short beam (nominal length $20 \mathrm{~mm}$, nominal thickness $7 \mathrm{~mm}$ ) into a silicone dog bone mold. The mold is then air-cooled by placing it in an acclimatized environment of $23^{\circ} \mathrm{C}$ and $50 \% \mathrm{RH}$. When the PCL is solidified, the silicone spacers are removed and epoxy resin is casted at both ends of the mold. The epoxy resin (EPIKOTE MGS RIMR135) and hardener (EPIKURE MGS RIMH137) were first mixed in a 100:30 mass ratio as recommended by the manufacturer using a mechanical stirrer and then placed under vacuum for 15 minutes in order to remove any trapped air introduced during mixing. The mold is then cured at a fixed temperature in an oven. Dummy specimens were used in order to monitor the temperature inside the epoxy resin with a thermocouple. After curing, the specimens are carefully demolded and tested for their tensile strength. An Instron 3369 tensile machine was used with wedge grips and a load cell of $2 \mathrm{kN}$. The tensile test was displacement controlled at a ratio of $1 \mathrm{~mm} / \mathrm{min}$. The maximum stress was calculated by correcting the maximum force by the surface area of the failed interface in the case of bond failure, or by the cross-section of the PCL block in the case of bulk failure.

Nanofiber veil preparation. PCL (Sigma-Aldrich, $M_{n} 80000 \mathrm{~g} \mathrm{~mol}^{-1}$ ) and PA6 nanofibers (Sigma-Aldrich, $M_{m} 51000 \mathrm{~g} \mathrm{~mol}^{-1}$ ) were electrospun from a formic acid (FA, Sigma-Aldrich, 98\%) / acetic acid (AA, Sigma-Aldrich, 98\%) solution according to previously reported procedures. ${ }^{[44,45]}$ The electrospinning was performed on an in-house developed multinozzle electrospinning machine. ${ }^{[46]}$ The PCL and PA6 nanofibers had average diameters of $345 \pm 150 \mathrm{~nm}$ and $195 \pm 35 \mathrm{~nm}$ respectively. Using a coaxial electrospinning nozzle (Raméhart Custom Needle, 100-10-COAXIAL-2016, outer needle: $1.7 \mathrm{~mm}$ OD, inner needle: $0.9 \mathrm{~mm}$ 


\section{WILEY-VCH}

OD), core-shell nanofibers were produced with a PA6 core and PCL shell. Two pumps (KD Scientific Pump Series 100) were used to feed the core (18 wt $\%$ PA6 in 50/50 FA/AA) and shell (8 wt\% PCL in 50/50 FA/AA) solutions, respectively. A high voltage power supply (Glassman High Voltage Series) was used to apply high voltage to the outer needle. The tip to collector distance (TCD), the flow rates (FR) of the solutions and the voltage were adjusted to obtain stable electrospinning and uniform coaxial nanofibers (TCD $=80 \mathrm{~mm}, \mathrm{~V}=30 \mathrm{kV})$. The nanofibers had a diameter of $235 \pm 30 \mathrm{~nm}$. The core/shell morphology was validated by dissolving the PCL shell with anisole after which the nanofibers were again analyzed with SEM. All nanofibrous veils were directly electrospun onto glass fiber mats (UDO ES500, unidirectional E-glass fibre mats, $500 \mathrm{~g} / \mathrm{m}^{2}$ ) with an areal density between $5-6 \mathrm{~g} \mathrm{~m}^{-2}$ for further use in reinforced composites. Representative SEM images of the nanofibers can be found in

\section{Figure 7.}

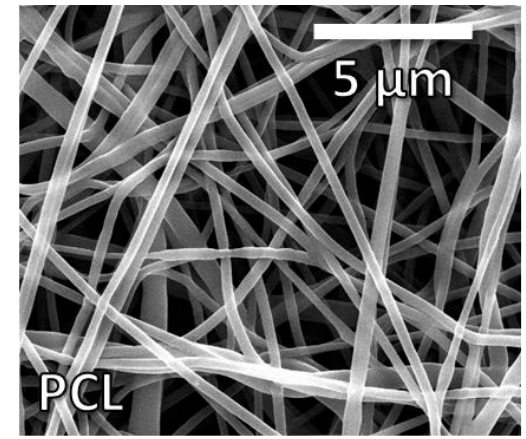

(a)

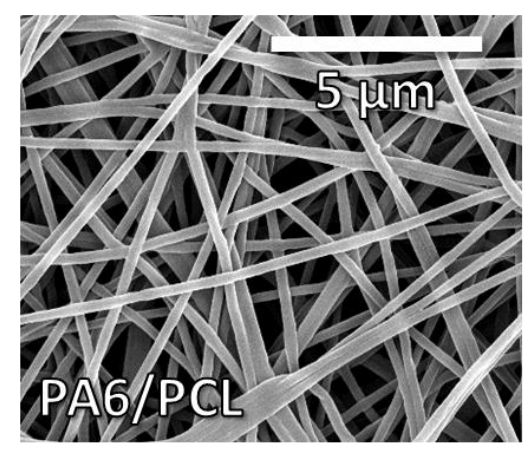

(c)

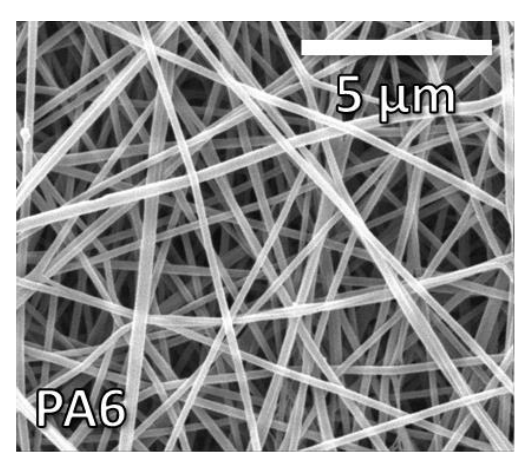

(b)

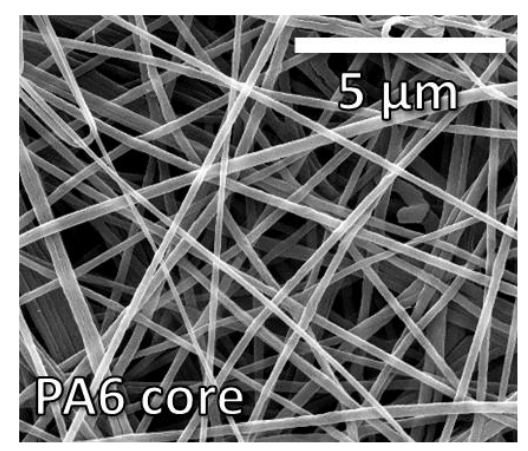

(d) 


\section{WILEY-VCH}

Figure 7: Representative SEM images of (a) PCL, (b) PA6 and (c) core/shell structured PA6/PCL nanofibers. The core structure is visualized in (d) after dissolving the PCL shell with anisole.

(Hybrid) composite laminate production. Unidirectional glass fiber reinforced (UDO ES500) composite laminates $\left[0^{\circ}\right]_{8}$ were produced by Vacuum Assisted Resin Transfer Moulding according to a previously reported procedure ${ }^{[34]}$ Briefly, 8 layers of the unidirectional glass fibre reinforcement are placed in a mould with fixed thickness $(3 \mathrm{~mm})$. For the hybrid laminates, the two middle plies consisted of a glass fiber ply with nanofibers spun on them (either PCL, PA6 or PA6/PCL) facing the midplane. A delamination initiation foil (ethylene tetrafluoroethylene based, $15 \mu \mathrm{m}$ thickness) is inserted in the midplane according to the ASTM D5528 standard to measure the Mode I interlaminar fracture toughness, represented as $G$ in this work. $^{[47]}$ The laminates had a thickness of $3 \mathrm{~mm}$ and a glass fibre volume fraction of $52 \mathrm{vol} \%$. The Mode I interlaminar fracture toughness was determined by Double Cantilever Beam (DCB) test using the modified beam theory method outlined in the ASTM standard. An Instron 3369 universal testing machine with a load cell of $500 \mathrm{~N}$ was used. Specimens were cut from the produced composite plates with a nominal length and width of $150 \mathrm{~mm}$ and $20 \mathrm{~mm}$ respectively. An initial delamination length of $50 \mathrm{~mm}$ was used and all specimens were precracked before performing the experiment. The $G$ value is determined at the $5 \% /$ max point on the measured load-displacement curves according to the procedure outlined in the ASTM standard.

Fracture surface analysis. A Jeol Quanta 200F Field Emission Gun SEM, a Phenom ProX SEM and an Olympus BX51 optical microscope were used to examine the fracture surface of the tested specimens.

\section{Supporting Information}

Supporting Information is available from the Wiley Online Library or from the author.

\section{Acknowledgements}




\section{WILEY-VCH}

D.R.D acknowledges the Fund for Scientific Research Flanders (FWO) through a postdoctoral fellowship. L.D. and K.D.C. gratefully acknowledge financial support from the Special Research Fund (BOF) Ghent University (BOF 13/24J/020, BOF BAS and

BOF.PDO.2015.0028.01) and from the Agency for Innovation by Science and Technology Flanders is gratefully acknowledged.

Received: ((will be filled in by the editorial staff))

Revised: ((will be filled in by the editorial staff)) Published online: ((will be filled in by the editorial staff $)$ ) 


\section{WILEY-VCH}

\section{References}

[1] C. Bruner, N. C. Miller, M. D. McGehee, R. H. Dauskardt, Adv. Funct. Mater. 2013, 23, 2863.

[2] N. Nordgren, H. Lönnberg, A. Hult, E. Malmström, M. W. Rutland, ACS Appl. Mater. Interfaces 2009, 1, 2098.

[3] X. Jin, L. Heepe, J. Strueben, R. Adelung, S. N. Gorb, A. Staubitz, Macromol. Rapid Commun. 2014, 35, 1551.

[4] N. D. Treat, M. A. Brady, G. Smith, M. F. Toney, E. J. Kramer, C. J. Hawker, M. L. Chabinyc, Adv. Energy Mater. 2011, 1, 82.

[5] J. Wieme, D. R. D’hooge, M.-F. Reyniers, G. B. Marin, Macromol. React. Eng. 2009, $3,16$.

[6] J. Yin, C. Lu, J. Fu, Y. Huang, Y. Zheng, Mater. Des. 2018.

[7] Y. Guo, X. Zuo, Y. Xue, Y. Zhou, Z. Yang, Y.-C. Chuang, C.-C. Chang, D. Gersappe, M. H. Rafailovich, Macromolecules 2018, acs. macromol.8b00297.

[8] A. M. Zolali, B. D. Favis, Macromolecules 2018, acs. macromol.8b00464.

[9] R. A. Ramli, W. A. Laftah, S. Hashim, RSC Adv. 2013, 3, 15543.

[10] H. Yang, L. Ye, J. Gong, M. Li, Z. Jiang, X. Wen, H. Chen, N. Tian, T. Tang, W. J. Blau, R. Harris, J. Douglas, Mater. Chem. Front. 2017, 54, 3524.

[11] P. Wang, X. Zhang, G. Lim, H. Neo, A. A. Malcolm, Y. Xiang, G. Lu, J. Yang, J. Mater. Sci. 2015, 50, 5978.

[12] L. Daelemans, S. van der Heijden, I. De Baere, H. Rahier, W. Van Paepegem, K. De Clerck, ACS Appl. Mater. Interfaces 2016, 8.

[13] Q. Cheng, B. Wang, C. Zhang, Z. Liang, Small 2010, 6, 763.

[14] S. Jiang, Y. Chen, G. Duan, C. Mei, A. Greiner, S. Agarwal, Polym. Chem. 2018.

[15] K. Bilge, E. Ozden-Yenigun, E. Simsek, Y. Z. Menceloglu, M. Papila, Compos. Sci. Technol. 2012, 72, 1639.

[16] H. Yano, J. Sugiyama, A. N. Nakagaito, M. Nogi, T. Matsuura, M. Hikita, K. Handa, Adv. Mater. 2005, 17, 153.

[17] Z.-M. Huang, Y.-Z. Zhang, M. Kotaki, S. Ramakrishna, Compos. Sci. Technol. 2003, 63, 2223.

[18] A. Romo-Uribe, L. Arizmendi, M. E. Romero-Guzmán, S. Sepúlveda-Guzmán, R. Cruz-Silva, ACS Appl. Mater. Interfaces 2009, 1, 2502.

[19] L. Daelemans, S. van der Heijden, I. De Baere, H. Rahier, W. Van Paepegem, K. De Clerck, Compos. Part A Appl. Sci. Manuf. 2017, 94, 10.

[20] Y. Dzenis, Science (80-. ). 2008, 319, 419.

[21] L. Daelemans, S. van der Heijden, I. De Baere, H. Rahier, W. Van Paepegem, K. De Clerck, Compos. Sci. Technol. 2015, 117, 244.

[22] G. W. Beckermann, K. L. Pickering, Compos. Part A Appl. Sci. Manuf. 2015, 72, 11.

[23] S. Hamer, H. Leibovich, A. Green, R. Avrahami, E. Zussman, A. Siegmann, D. Sherman, Compos. Sci. Technol. 2014, 90, 48.

[24] E. Özden, Y. Z. Menceloğlu, M. Papila, ACS Appl. Mater. Interfaces 2010, 2, 1788.

[25] E. Özden-Yenigün, Y. Z. Menceloğlu, M. Papila, ACS Appl. Mater. Interfaces 2012, 4, 777.

[26] J. Zhang, T. Yang, T. Lin, C. H. Wang, Compos. Sci. Technol. 2012, 72, 256.

[27] A. Cohades, E. Manfredi, C. J. G. Plummer, V. Michaud, Eur. Polym. J. 2016, 81, 114.

[28] X. Luo, R. Ou, D. E. Eberly, A. Singhal, W. Viratyaporn, P. T. Mather, ACS Appl. Mater. Interfaces 2009, 1, 612.

[29] P. M. Remiro, M. M. Cortazar, M. E. Calahorra, M. M. Calafel, Macromol. Chem. Phys. 2001, 202, 1077.

[30] J. Rotrekl, L. Matějka, L. Kaprálková, A. Zhigunov, J. Hromádková, I. Kelnar, Express 


\section{WILEY-VCH}

Polym. Lett. 2012.

[31] J. Hu, C. Yin, H.-Q. Mao, K. Tamada, W. Knoll, Adv. Funct. Mater. 2003, 13, 692.

[32] S. M. Kang, S. Park, D. Kim, S. Y. Park, R. S. Ruoff, H. Lee, Adv. Funct. Mater. 2011, $21,108$.

[33] J.-L. Chen, F.-C. Chang, Macromolecules 1999, 32, 5348.

[34] S. van der Heijden, L. Daelemans, B. De Schoenmaker, I. De Baere, H. Rahier, W. Van Paepegem, K. De Clerck, Compos. Sci. Technol. 2014, 104, 66.

[35] M. Ghasemi, A. Y. Singapati, M. Tsianou, P. Alexandridis, AIChE J. 2017, 63, 1368.

[36] P. (Partho) Neogi, Diffusion in polymers; Marcel Dekker, 1996.

[37] D. R. D'hooge, P. H. M. Van Steenberge, M.-F. Reyniers, G. B. Marin, Prog. Polym. Sci. 2016, 58, 59.

[38] P. A. Mueller, G. Storti, M. Morbidelli, Chem. Eng. Sci. 2005, 60, 1911.

[39] L. G. Aguiar, D. C. Iwakura, A. T. S. Semeano, R. W. C. Li, E. F. Souza, J. Gruber, R. Giudici, Can. J. Chem. Eng. 2018, 96, 1221.

[40] Madeleine C. Griffiths, Jelica Strauch, and Michael J. Monteiro, R. G. Gilbert*, 1998.

[41] J. S. Vrentas, C. M. Vrentas, J. Polym. Sci. Part B Polym. Phys. 2003, 41, 501.

[42] K. Allaer, I. De Baere, W. Van Paepegem, J. Degrieck, Polym. Test. 2015, 42, 199.

[43] L. Daelemans, S. van der Heijden, I. De Baere, H. Rahier, W. Van Paepegem, K. De Clerck, Compos. Sci. Technol. 2016, 124, 17.

[44] L. Van der Schueren, B. De Schoenmaker, Ö. I. Kalaoglu, K. De Clerck, Eur. Polym. J. 2011, 47, 1256.

[45] B. De Schoenmaker, S. Van der Heijden, I. De Baere, W. Van Paepegem, K. De Clerck, Polym. Test. 2013, 32, 1495.

[46] P. Westbroek, T. Van Camp, S. De Vrieze, K. De Clerck, Production and use of laminated nanofibrous structures 2008.

[47] ASTM Standard D5528, Standard Test Method for Mode I Interlaminar Fracture Toughness of Unidirectional Fiber Reinforced Polymer Matrix Composites. ASTM Int. 2013.

[48] L. G. Aguiar, D. C. Iwakura, A. T. S. Semeano, R. W. C. Li, E. F. Souza, J. Gruber, R. Giudici, Can. J. Chem. Eng. 2018, 96, 1221.

[49] J. S. Vrentas, J. L. Duda, J. Polym. Sci. Polym. Phys. Ed. 1977, 15, 417.

[50] J. S. Vrentas, J. L. Duda, J. Polym. Sci. Polym. Phys. Ed. 1977, 15, 403.

[51] S.-U. Hong, Ind. Eng. Chem. Res. 1995, 34, 2536.

[52] R. N. Haward, J. Macromol. Sci. Part C Polym. Rev. 1970, 4, 191.

[53] S. Kobuchi, Y. Arai, Prog. Polym. Sci. 2002, 27, 811.

[54] W. W. Graessley, J. Polym. Sci. Polym. Phys. Ed. 1980, 18, 27.

[55] D. R. D’hooge, M.-F. Reyniers, F. J. Stadler, B. Dervaux, C. Bailly, F. E. Du Prez, G.

B. Marin, Macromolecules 2010, 43, 8766. 


\section{WILEY-VCH}

Excellent nanofiber adhesion for hybrid polymer materials with high toughness based on matrix interdiffusion during chemical conversion

A direct route that enables to control interfacial bonding between two polymeric materials is proposed, with molecular diffusion, i.e. interdiffusion, during in situ chemical formation of one of those materials. The route allows to increase the toughness of nanofibrous hybrid materials with $G$ values over $600 \mathrm{~J} \mathrm{~m}^{-2}$ (up to $65 \%$ improvement) for optimally designed curing temperature history and fiber morphology, including core-shell configurations.
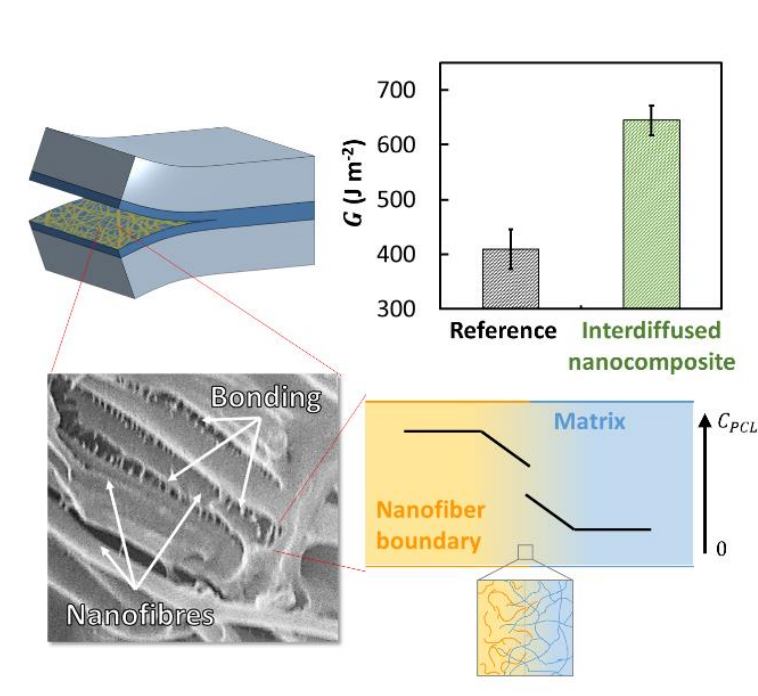

Copyright WILEY-VCH Verlag GmbH \& Co. KGaA, 69469 Weinheim, Germany, 2016. 


\section{WILEY-VCH}

\section{Supporting Information}

Excellent nanofiber adhesion for hybrid polymer materials with high toughness based on matrix interdiffusion during chemical conversion

Lode Daelemans, Wim Van Paepegem, Dagmar R. D'hooge*, and Karen DE CLERCK*

Section S1: Two film layer model to predict the cure induced interdiffusion mechanism: Model development

\section{Main theoretical framework}

Upon the contact of the poly( $\varepsilon$-caprolactone) (PCL) phase (phase 1) with the resin phase (phase 2) a strong concentration gradient is established as no PCL is present in the latter phase and a certain solubility can be expected for PCL molecules in the resin environment. A natural question that arises is how easily the PCL interdiffusion can take place, taking into account that the PCL phase consists of entangled molecules with limited mobility and the resin phase is converted in a viscous polymer network with increasing contact time and thus at one point further diffusion and accumulation in the epoxy phase is blocked.

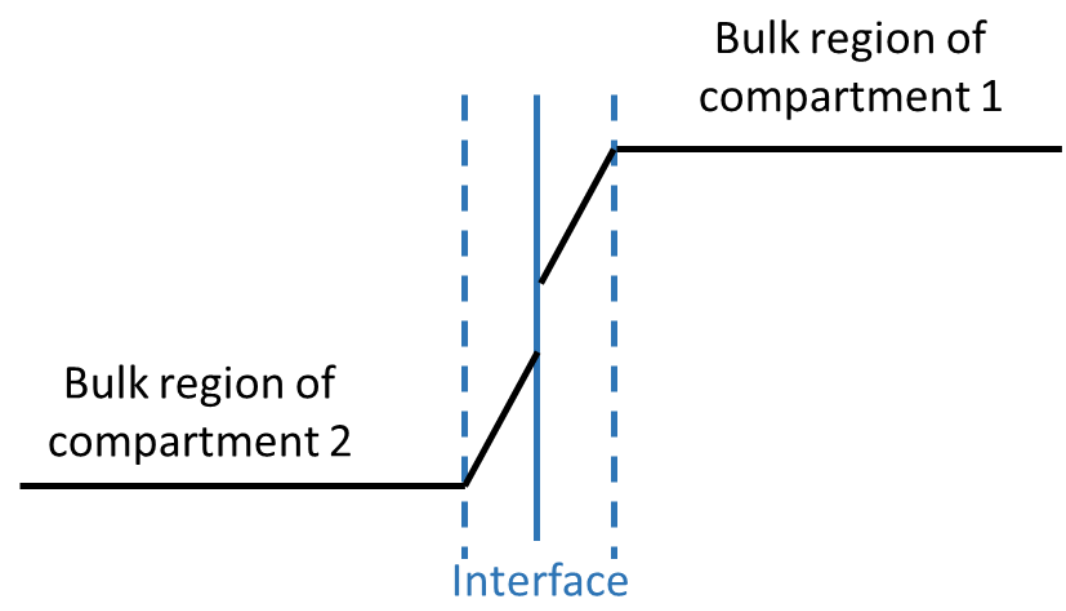

Figure S1: Principle of two film layer model to account for interdiffusion of PCL molecules from the PCL (rich-)phase to the reacting resin phase; depicted at a given time.

In the present work, a two film layer model is considered to describe the PCL interdiffusion. Bulk concentrations are assumed outside the layers $\left(C_{i}, i=1,2\right)$ and each film layer (thickness 


\section{WILEY-VCH}

$\left.\delta_{i} ; i=1,2\right)$ grasps the resistance to PCL transport in the selected phase, as depicted in Figure S1 (related to Figure 2(a) in the main text). The capability toward mass transport in each layer is reflected by a mass transfer coefficient $k_{i}(i=1,2)$, as defined by the ratio of the diffusion coefficient in that phase $\left(D_{i}\right)$ to the film layer thickness $\left(\delta_{i}\right):^{[5,38]}$

$$
k_{i}=\frac{D_{i}}{\delta_{i}}
$$

A lower diffusivity and a higher film thickness thus contribute to a slower interdiffusion. At the interface $(f)$ equilibrium is assumed with the partitioning coefficient $\Gamma$ defined as the ratio of the interface PCL concentration for phase 1 to the one for phase $2\left(\Gamma=C_{1, f} / C_{2, f}\right)$. Limited information is available with respect to this thermodynamic parameter for the selected twophase system. A much higher affinity can although be expected for the PCL phase (phase 1) under equilibrium conditions. In the present work, this parameter is considered as constant at low curing conversions (up to 20\%) selecting a value of 100 .

Based on Figure S1 and in the absence of accumulation in the film layer, which is assumed in the present work, the molar flux $J\left(\mathrm{~mol} \mathrm{~m}^{-2} \mathrm{~s}^{-1}\right)$ - with a positive sign for a movement from phase 1 to phase 2 - can be written as:

$$
J=k_{1}\left(C_{1}-C_{1, f}\right)=k_{2}\left(C_{2, f}-C_{2}\right)
$$

Considering the $\Gamma$ definition, the molar flux can be expressed solely based on the bulk concentrations (convention: phase 1 as reference):

$$
J=K\left(C_{1}-\Gamma C_{2}\right)
$$

The overall transport coefficient $K$, which reflects restrictions in mobility in each phase, in Equation (S3), is given by: ${ }^{[5,38,48]}$ 


$$
K=\frac{1}{\left(\frac{1}{k_{1}}+\frac{\Gamma}{k_{2}}\right)}
$$

The initial flux $J_{0}$ is thus given by:

$$
J_{0}=\frac{C_{1,0}}{\left(\frac{1}{k_{1}}+\frac{\Gamma}{k_{2}}\right)}
$$

with $C_{1,0}$ the initial PCL concentration in phase 1, which follows from dividing the bulk density by the mass average molar mass for the PCL phase.

At $t=\Delta t$ the amount of moles that has undergone interdiffusion can be assessed by multiplying $J_{0}$ (Equation (5a)) by $\Delta t$ and the contact area $(A)$. The new concentrations $C_{1, \Delta t}$ and $C_{2, \Delta t}$ can be subsequently obtained by accounting for the volume of the phases $\left(V_{l}\right.$ and $\left.V_{2}\right)$.

Similarly, discrete updates at later times $(t$ to $t+\Delta t)$ can be made based on Equation (S5b) instead of Equation (S5a);

$$
J_{t}=\frac{\left(C_{1, t}-\Gamma C_{2, t}\right)}{\left(\frac{1}{k_{1}}+\frac{\Gamma}{k_{2}}\right)}
$$

Note that the latter equation is Equation (1) in the main text. To apply it, the model parameters need to be calculated properly, as covered below.

\section{Calculation of model parameters}

In Equation (S5), the mass transfer coefficients $k_{1}$ and $k_{2}$ need to be known (Equation (S1)). Hence, the corresponding PCL diffusion coefficients $\left(D_{1}\right.$ and $\left.D_{2}\right)$ and layer thicknesses $\left(\delta_{1}\right.$ and $\delta_{2}$ ) need to be determined. The calculation of the former type of parameters is explained below and the latter type of parameters are seen as adjustable. Taking into account the qualitative scope of the simulations they are taken as $1 \%$ of the length axis for diffusion. The latter follows from diving $V_{i}$ by the contact area $A$. 


\section{WILEY-VCH}

The PCL diffusion coefficients are calculated based on the frequently applied free volume theory (FVT), in which the diffusion of a molecule is described by jumping (of part) of the molecule into the free holes as created by the mixture of all molecules present. ${ }^{[49,50]}$ The theory predicts a lower diffusion coefficient for molecules that are larger and/or mixtures with less total free hole volume.

The diffusivity of a PCL molecule in a given mixture should in the limit, i.e. for very low chain lengths, become similar to the one of the "ring-opened" CL monomer. Hence, it is worthwhile to focus first on the calculation of such monomer diffusion coefficient.

\section{“Ring-opened” monomer diffusion coefficient (limit for chain length of 1)}

According to the FVT a monomer diffusion coefficient in a phase $i\left(D_{m, i}\right)$ can be assessed based on:

$$
D_{m, i}=\overline{D_{m, l, 0}} \exp \left[-M_{m, j u m p, i} \widehat{V}_{m, i} * \frac{\frac{\omega_{m, i}}{M_{m, j u m p, i}}+\frac{\omega_{p, i}}{M_{p, j u m p, i}}}{\frac{\widehat{V}_{F H, i}}{\gamma_{i}}}\right]
$$

in which $\overline{D_{m, l, 0}}$ is the average pre-exponential factor describing on an average basis (e.g. at an average temperature) how feasible a diffusional monomer jump can be executed in phase $i$, $M_{m / p, j u m p, i}$ is the molar mass of a jumping unit for monomer/polymer diffusion in phase $i, \widehat{V}_{m, i}{ }^{*}$ is the specific volume needed for jumping of monomer molecules in phase $i, w_{m / p, i}$ is the mass fraction of monomer/polymer ${ }^{1}$ in phase $i$ neglecting the mass fractions of the other components present in the mixture, $\widehat{V}_{F H, i}$ is the total hole free volume per mass basis for phase $i$, and $\gamma_{i}$ is an overlap factor to correct for the competition of several molecules for the same available hole free volume in phase $i$.

\footnotetext{
${ }^{1}$ For a mixture with several monomers/polymers $(a=1,2, \ldots), w_{m / p, i}$ needs to be extended into $w_{m / p a, i} ;$ e.g. for the resin phase $w_{m 1,2}$ and $w_{m 2,2}$ need to be introduced and thus also $M_{m 1, j u m p, 2}$ and $M_{m 2, j u m p, 2}$.
} 


\section{WILEY-VCH}

For several non-macromolecules, average pre-exponential factors have been determined based on regression analysis to pure monomer viscosity data. ${ }^{[37]}$ An average is afforded as the activation energy for the actual jump is limited and the temperature dependency is mainly relevant for the variation of the available space. Since to best of the authors' knowledge no parameters have been reported for the "ring-opened" CL monomer, in the present work, $\overline{D_{m, l, 0}}$ for methyl acetate has been utilized, taking into account its similar size. ${ }^{[51]}$ To a first approximation $M_{m / p, j u m p, i}$ in Equation (S6) can be taken equal to the monomer molar mass. Furthermore, $\widehat{V}_{m, i}{ }^{*}$ in Equation (S6) can be obtained from group contribution methods. ${ }^{[52]}$ In the present work, a reported value for methyl acetate has been used in line with the aforementioned assumption.

Assuming additivity $\widehat{V}_{F H, i}$ in Equation (S6) can be calculated as:

$$
\frac{\hat{V}_{F H, i}}{\gamma_{i}}=\omega_{m, i} \frac{\hat{V}_{F H m, i}}{\gamma_{m, i}}+\omega_{p, i} \frac{\hat{V}_{F H p, i}}{\gamma_{p, i}}
$$

in which $\widehat{V}_{F H m / p, i}$ is the pure monomer/polymer total hole free volume contribution and $\gamma_{m / p, i}$ is the corresponding overlap factor. A key difference between phase 1 (PCL) and phase 2 (resin) is that the former phase is non-reactive and the latter reactive. Phase 1 possesses a more or less constant composition $\left(\omega_{p, 1} \approx 1\right)$, as the impact of PCL going out of this phase and resin monomer (or even epoxy polymer) entering this phase can be ignored to a first approximation. Phase 2 has in contrast a strongly varying composition, with a decreasing mass fraction for (resin) monomer and an increasing mass fraction for (epoxy) polymer. Moreover, the topology of the polymer in this reactive phase is altering from a linear to a network structure.

The individual contributions in Equation (S8) follow from: ${ }^{[49,50]}$ 


$$
\begin{gathered}
\frac{\widehat{V}_{F H m, i}}{\gamma_{m, i}}=\frac{K_{11, i}}{\gamma_{m, i}}\left(K_{21, i}+T-T_{g m, i}\right) \\
\frac{\widehat{V}_{F H p, i}}{\gamma_{p, i}}=\frac{K_{12, i}}{\gamma_{p, i}}\left(K_{22, i}+T-T_{g p, i}\right)
\end{gathered}
$$

in which $K_{11, i} / \gamma_{m, i}, K_{12, i} / \gamma_{p, i}, K_{21, i}-T_{g m, i}$, and $K_{22, I}-T_{g p, i}$ are pure free hole volume parameters with $T_{g p, i}$ the polymer glass transition temperature and $T_{g m, i}$ the formally analogous monomer glass transition temperature in phase $i$.
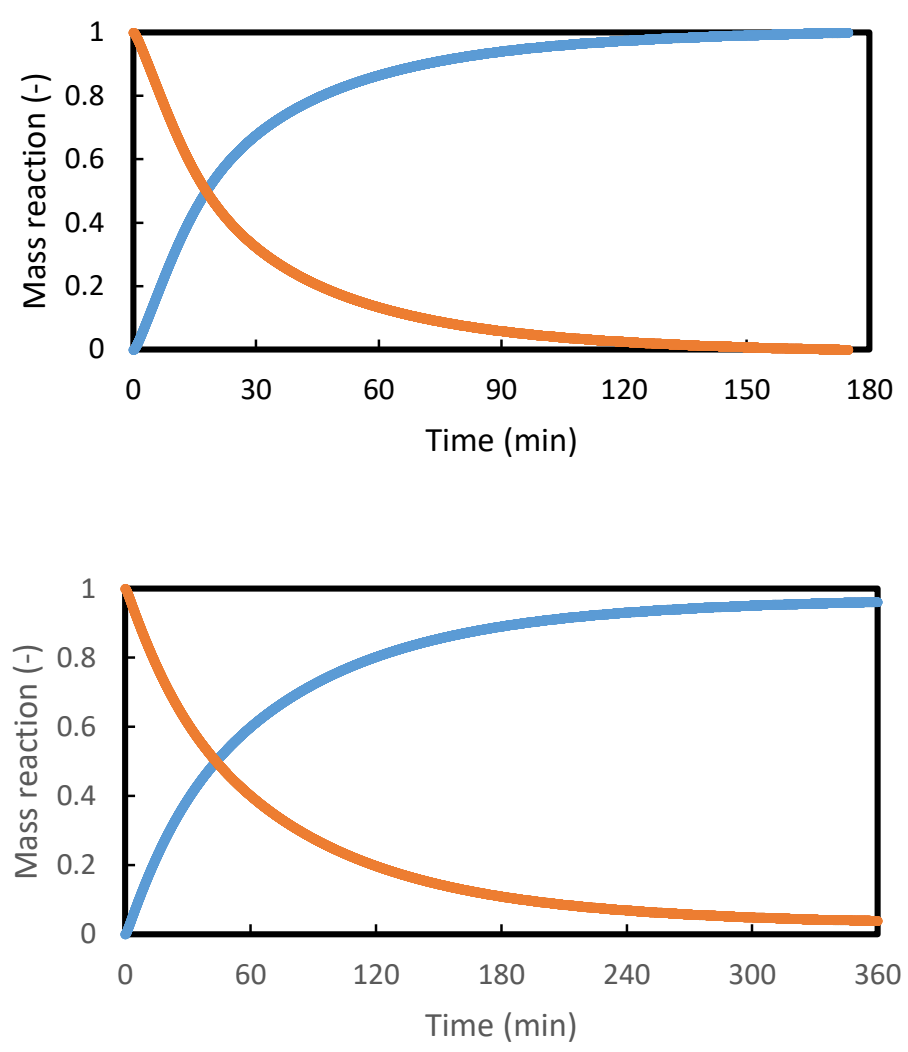

Figure S2: DSC data to assess the time dependence of the mass fractions in the resin phase $\left(w_{m, 2}\right.$ (orange) and $w_{p, 2}$ (blue) so that Equation (6)-(10) can be calculated as a function of time; shown for isothermal case of $80^{\circ} \mathrm{C}$ (top) and $65^{\circ} \mathrm{C}$ (bottom).

The aforementioned parameters can be determined based on regression analysis to dynamic viscosity data of pure components. ${ }^{[37]}$ For the polymer related parameters, a direct link exists with the William-Landel-Ferry (WLF) parameters $\left(C_{1, i}\right.$ and $\left.C_{2, i}\right): K_{2 l, i}=\hat{V}_{p, i}{ }^{*} /\left(2.303 C_{2, i} C_{l, i}\right)$ and $K_{22, i}=C_{2, i}{ }^{[53]}$ In the present work, for simplicity, the universal WLF parameters are 


\section{WILEY-VCH}

employed $\left(C_{1, i}=17.4\right.$ and $\left.C_{2, i}=51.6 \mathrm{~K}\right)$. Note that the contribution of (pure) "ring-opened" CL monomer (Equation (S8), $i=1$ ) can be ignored as for the application of the model $w_{p, l}$ can be seen as 1, as highlighted above. For the resin phase, in principle, Equation (S10) needs to be applied twice as two monomers (epoxy monomer and hardener (amine)) are present. For simplicity, a theoretical "average" so single resin monomer is considered in the present work so that Equation (S8) suffices in combination with Equation (S6). This theoretical monomer is given the pure diffusion properties of $n$-hexyl benzene to mimic a restricted mobility as to be expected based on the typical size of resin monomers. ${ }^{[51]}$

Finally, the mass fractions in the resin phase $\left(w_{m, 2}\right.$ and $\left.w_{p, 2}\right)$ can be obtained as a function of time $(t)$ from DSC measurements, with two examples as recorded in the present work provided in Figure S2. Complete conversion is associated with a flattening of the DSC cumulative heat per surface area. Note that this link with DSC data makes that the model inherently accounts for the variation of the available spaces for diffusion as a function of temperature and time, and thus highlight the validated character of the model.

\section{Polymer diffusion coefficient (values for other chain lengths starting from previous insights}

\section{for a chain length of 1)}

For a polymer (PCL) molecule possessing a chain length $j$, the diffusion coefficient in phase $i$, i.e. the polymer diffusion coefficient $D_{p, i}(j)$, can be approximated taking $D_{m, i}$ as the starting point:

$$
D_{p, i}=\frac{D_{m, i}}{j^{g_{i}\left(w_{p, i}\right)}}
$$

in which $g_{i}$ is a function in general depending on $w_{p, i}$. In practice and in the present work, $j$ can be replaced by e.g. the number-average chain length $x_{n}$. 


\section{WILEY-VCH}

For phase 1, consisting of entangled PCL molecules, the reputation theory (as derived for polymer melts) is assumed in the present work and $g_{l}$ can be given a constant value of $2 .{ }^{[54]}$ For the reactive phase 2 , in agreement with previous studies on describing diffusivities in polymerization processes, $g_{2}$ is assessed using a universal correlation, i.e. $0.664+2.02 w_{p, 2 .}{ }^{[40]}$ Under diluted conditions (low viscosities) this correlation predicts a Stokes-Einstein type of diffusion behavior, whereas at very high monomer conversions (very high viscosities) a diffusion behavior somewhat similar to the reputation theory is reflected ( $g_{l}$ for instance equal to 2 at $w_{p, 2}$ equal to 0.7$) .{ }^{[55]}$ Hence, the diffusion model in phase 2 accounts for a change in mobility and diffusivity due to configurational changes. Strictly the universal correlation has been derived for more linear polymer systems and is thus valid for the lower monomer conversion range of the epoxy curing. However, to a first approximation and taking into account the scope of the theoretical derivation, it can also be applied for the higher monomer conversion range in the present work.

\section{Parameters}

Table S1 gives an overview of the parameter values to enable the calculation of $D_{p, i}$ (Equation (S10); $i=1$ (PCL phase) , $i=2$ (resin phase)). These parameters, which are literature based $^{[40,51,53,55]}$, allow a qualitative description of the PCL interdiffusion as a function of reaction time, temperature and viscosity changes, which is the scope of the theoretical derivation in the present work. 
Table S1: Overview of parameters enabling the calculation of the PCL diffusion coefficient in PCL and resin phase (phase 1 and 2; Equation (S6)-(S10)).

\begin{tabular}{|c|c|c|}
\hline & Phase $1(i=1)$ & Phase $2(i=2)$ \\
\hline$D_{m, i, 0}\left(\mathrm{~m}^{2} \mathrm{~s}^{-1}\right)$ & $5.210^{-8 a}$ & $5.210^{-8 b}$ \\
\hline$M_{m, j u m p, i}\left(\mathrm{~g} \mathrm{~mol}^{-1}\right)$ & 113.16 & 113.16 \\
\hline$\widehat{V}_{m, i}^{*}\left(\mathrm{~m}^{3} \mathrm{~kg}^{-1}\right)^{\mathrm{a}}$ & $0.85510^{-3}$ & $0.85510^{-3}$ \\
\hline$K_{11, i} / \gamma_{m, I}\left(\mathrm{~m}^{3} \mathrm{~kg}^{-1} \mathrm{~K}^{-1}\right)$ & $-c$ & $2.8710^{-6 \mathrm{a}, \mathrm{d}}$ \\
\hline$K_{21, i}-T_{g m, i}(\mathrm{~K})$ & $-c$ & $-162.46^{\mathrm{a}, \mathrm{d}}$ \\
\hline$K_{12, i} / \gamma_{p, i}\left(\mathrm{~m}^{3} \mathrm{~kg}^{-1} \mathrm{~K}^{-1}\right)^{\mathrm{e}}$ & $0.85510^{-3} / 51.6 / 17.4$ & $0.99010^{-3} / 51.6 / 17.4$ \\
\hline$K_{22, i}-T_{g p, i}(\mathrm{~K})^{\mathrm{e}}$ & $51.6-(273-60)$ & 51.6- $(273+75)$ \\
\hline$x_{n}(-)^{\mathrm{g}}$ & 700 & $500^{\mathrm{f}}$ \\
\hline$g(-)^{\mathrm{h}}$ & 2 & $0.664+2.02 w_{p, 2}$ \\
\hline$V\left(\mathrm{~m}^{3}\right)^{\mathrm{i}}$ & $5.010^{-7}$ & $3.010^{-6}$ \\
\hline \multicolumn{3}{|c|}{ 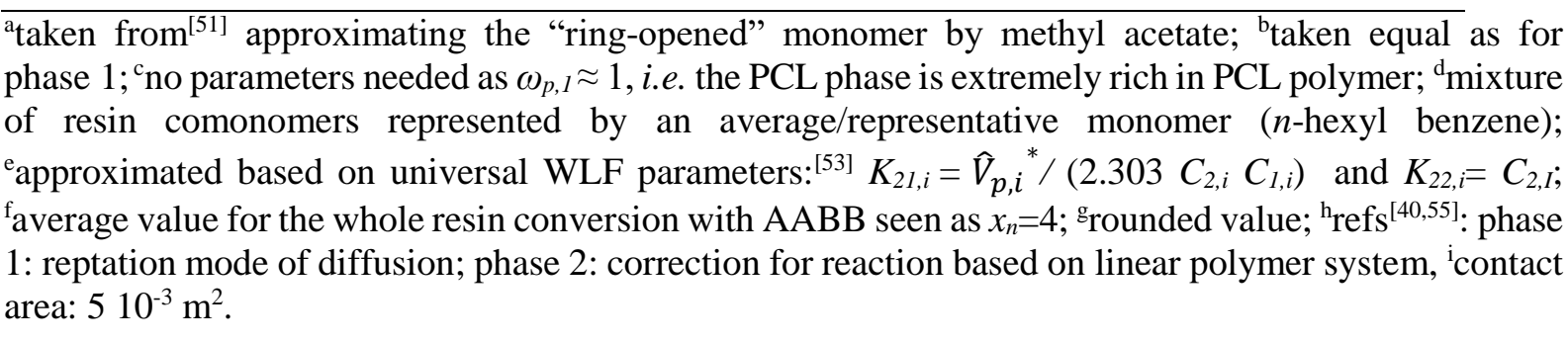 } \\
\hline
\end{tabular}




\section{WILEY-VCH}

Section S2: Two film layer model to predict the cure induced interdiffusion mechanism: Results (figures also included in the main text).

Figure S3 (also in the main text) displays for a curing temperature of $65^{\circ} \mathrm{C}$ (yellow line) and $80^{\circ} \mathrm{C}$ (blue line) the molar flux of PCL from phase 1 (PCL phase) to phase 2 (resin phase). It can be seen that at low reaction times a higher flux is obtained at a higher temperature. However, due to a shorter reaction time, the flux is reduced more strongly afterwards, taking into account the stronger relevance of polymer network formation. At each temperature the driving force for PCL movement is also influenced by the time history, i.e. a lesser concentration gradient is obtained regardless of the further restriction in mobility as a consequence of network formation.

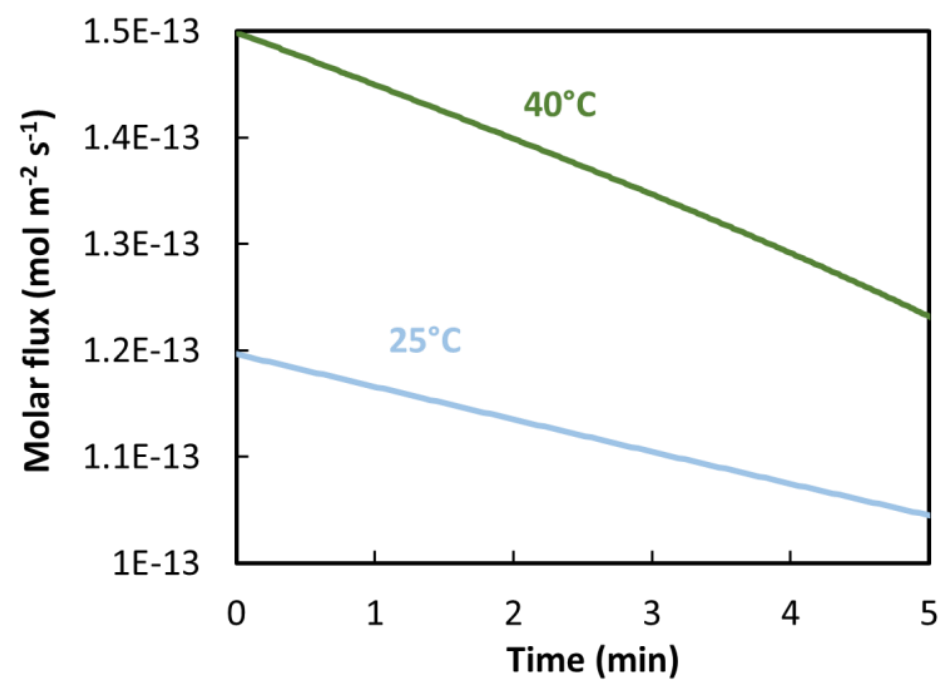

Figure S3: Molar flux as calculated based on Equation (S5)-(S10) and Table S1; isothermal cases: orange line: $25^{\circ} \mathrm{C}$ and blue line: $40^{\circ} \mathrm{C}$.

Figure S4 (also in the main text) presents the corresponding increases in PCL concentration in the reacting resin phase. For a full curing, more diffusion has occurred at a lower curing temperature. 
WILEY-VCH

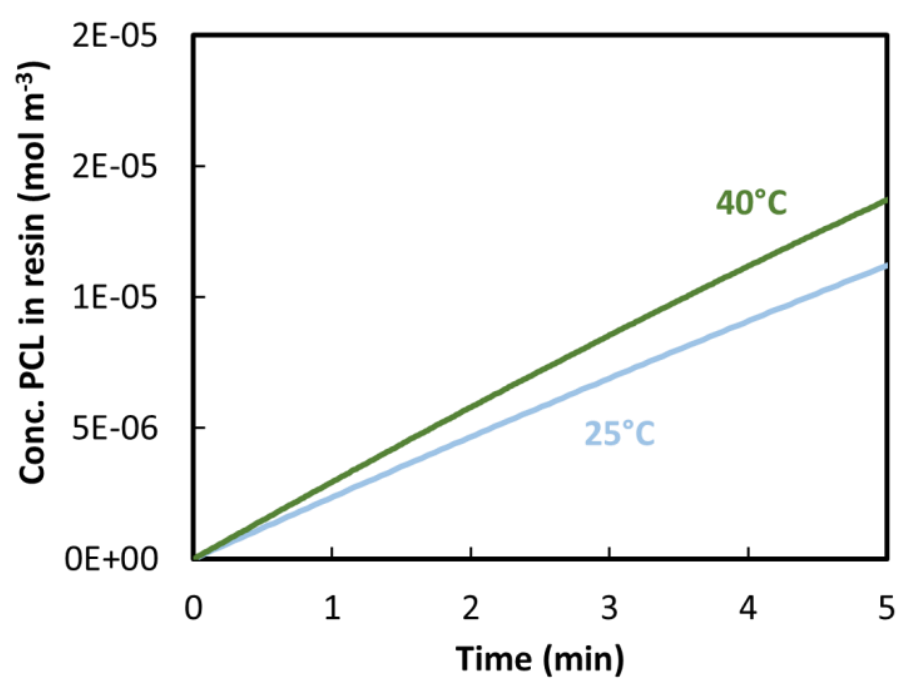

Figure S4: Corresponding increases in PCL concentration in resin phase for Figure S3. 